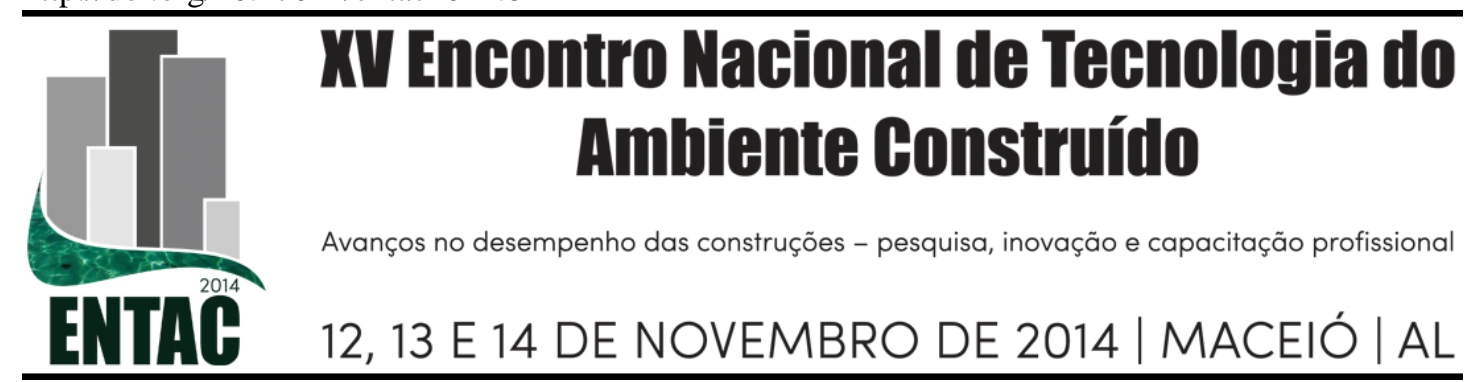

\title{
A NOVA NBR 13755
}

\section{JUNGINGER, MAX (1)}

(1) Coordenador CE 189-000:03, email: maxjgg@gmail.com

\begin{abstract}
RESUMO
O problema de destacamento de placas cerâmicas em fachadas é um fato que provoca preocupação sempre que este tipo de revestimento é especificado. Se, por um lado, a solução deste problema não é uma tarefa fácil, certamente parte dela passa pela existência de um projeto de revestimento de fachada suficientemente detalhado. Dentro deste contexto, a ABNT criou a comissão de estudos (CE 189:000-03) das cinco normas brasileiras de revestimentos cerâmicos: NBR 8214 (1983), 9817 (1987), 13753 (1996), 13754 (1996) e 13755 (1996). Este artigo, então, tem o objetivo de expor as atividades do comitê, suscitando o aparecimento de críticas e sugestões para o novo corpo das normas. Iniciados os trabalhos pela norma de fachadas (13755), estão previstas grandes alterações no corpo do texto, tanto conceituais como de detalhes. O item 5.1. Juntas, foi completamente remodelado e três tipos de juntas estão citados: estrutural, movimentação e assentamento. Para as juntas de movimentação foram definidas situações típicas de uso, posicionamento, cuidados e geometrias possíveis. Outros fatores, como existência de projeto, tipo de fiscalização, flutuação térmica de longo e curto prazo do local, características das placas e propriedades do emboço e argamassa adesiva também estão sob análise, tudo com o objetivo de compilar fatores críticos do revestimento sob a ótica da visão sistêmica do edifício. Ainda que o novo documento contemple qualquer tipo de placa cerâmica, inclusive pastilhas, um texto de norma não pode abarcar todas as situações possíveis na prática, motivo por que irá sugerir a consulta a um especialista no assunto para que um mínimo de esforço no projeto de revestimento seja despendido ainda na fase de concepção do edifício.
\end{abstract}

Palavras-chave: revestimento cerâmico, juntas de fachada, projeto de revestimento.

\begin{abstract}
Delaminating of ceramic tiles is a problem that worries designers always this type of finishing is present. Although the solution to this problem is not an easy one, it certainly involves a good design. Thinking about that, ABNT has created a technical committee to review some Brazilian standards: 8214 (1983), 9817 (1987), 13753, 13754 and 13755 (1996). The objective of this article is to describe what has been done so far and more contributions from many people can be compiled. NBR 13755 is the first standard to be revised and some big adjustments are about to happen. The item 5.1 Joints was reformulated at all and three types of joints are shown: structural, movement and grout joint. For the movement joints, typical situations of use, positioning and geometry were defined. Other factors, like design, type of on-site inspection, short and long-term thermal variations, tile properties, render and mortar properties are also under analysis, all with the goal of summarizing critical factors that contribute to the stability of the ceramic tiling. This standard is for any type of ceramic tile, even mosaics, but it is impossible to describe all the situations. So, in those cases, specific details should be specified by the designer/architect.
\end{abstract}

Keywords: ceramic tiling, joints, external renderings design.

\section{INTRODUÇÃO}

A NBR 13755 - Revestimento de paredes externas e fachadas com placas cerâmicas e com utilização de argamassa colante - Procedimento (ABNT, 1996) é a norma brasileira que orienta a execução de revestimentos cerâmicos de fachada. Datado de 1996, o 
texto se aplica a placas com área de superfície de até $400 \mathrm{~cm}^{2}$ e espessura máxima de $15 \mathrm{~mm}$, excluídas as pastilhas.

Ocorre que esta abrangência, com o crescente uso de placas de dimensões superiores, deixa uma parcela dos revestimentos cerâmicos executados no país "sem" embasamento técnico. Entenda-se aqui "sem" como a ausência de um documento formal que englobe e descreva a execução do revestimento com o uso de pastilhas e placas de área superior a $400 \mathrm{~cm}^{2}$. Existem, sim, outros documentos importantes, como publicações acadêmicas, artigos publicados em anais diversos e os compêndios do Qualicer.

Este artigo, então, não possui o objetivo de relatar resultados de ensaios ou pesquisas científicas, mas sim de expor as profundas alterações do texto da NBR 13755 num evento com a participação de inúmeros elos da cadeia produtiva, elos estes capazes de dar contribuições importantes para a consolidação do texto final da referida norma.

\section{PROJETO DE REVESTIMENTO}

\subsection{Aspectos gerais}

O projeto de revestimento visa produzir detalhes construtivos e especificações técnicas de materiais e métodos construtivos adequados a cada situação. As diversas camadas que compõem o sistema, se fossem de movimentação livre, apresentariam comportamento bastante diferenciado daquele que apresentam quando imersas no sistema, que impõe restrições e leva ao surgimento de esforços internos. Tais esforços tendem a ser tão mais expressivos quanto mais rígidas as camadas e, caso atinjam valores excessivos, podem levar ao surgimento de fissuras, perda de aderência e outros problemas.

Inúmeras são as variáveis que influenciam o desenvolvimento de um projeto, várias delas discutidas por Goldberg (2011), pela AS 3958.2 (AS, 1992), pela BS 5385.2 (BSI, 2006) e por outros textos, não menos relevantes. Desta forma, o projetista de revestimento precisa levar em consideração alguns fatores importantes no desenvolvimento do projeto, dentre os quais se destacam:

- estabilidade global da edificação: concreto moldado in loco, alvenaria estrutural, concreto pré-moldado, estrutura metálica etc;

- cronograma de execução da estrutura;

- exigências arquitetônicas: modulação das placas em função do tamanho dos panos e da presença de juntas de movimentação;

- tipo de substrato: rigidez, resistência mecânica e resistência superficial;

- características e propriedades das placas: tamanho, cor e dilatação térmica, absorção de água, expansão por umidade (EPU), esmaltação;

- características e propriedades da argamassa colante: aderência e capacidade de absorver deformações;

- características e propriedades do rejunte: rigidez, aderência à lateral das placas, resistência mecânica;

- variação térmica: condições climáticas a curto e médio prazos, insolação das fachadas, temperatura à época do assentamento;

Com base nestes dados de entrada e em outros que o projetista julgar importantes, a comissão de estudos julgou prudente que o projeto de revestimento deve conter, no mínimo, as especificações seguintes: 
- a modulação das placas, que deve ser desenvolvida de modo a evitar que se usem frações de placas cerâmicas. Recortes e regras a serem adotadas em caso de exceções devem ser previstos;

- detalhes construtivos: encontro das placas em quinas internas e externas; encontro com esquadrias, peitoris, pingadeiras; detalhes de requadro de vãos etc;

- tipo de substrato e sua forma de produção e controle, bem como especificação de reforços quando necessário;

- tipo de argamassa colante;

- largura das juntas de assentamento e tipo de rejunte;

- tamanho dos panos de revestimento;

- especificação das juntas de movimentação: geometria, posição, técnica de execução;

- técnica de assentamento das placas e ferramentas utilizadas;

- cuidados especiais durante a etapa de produção, caso necessários.

Tais especificações devem ser dadas na forma de texto, esquemas, detalhes construtivos ou quaisquer outros meios que o projetista julgue prudente de modo a evitar dúvidas quando da leitura do projeto.

Uma vez que as variáveis de entrada são numerosas e contemplá-las em um único texto ou tabela é impraticável, existe a tentativa de criação de uma tabela com a ponderação de alguns fatores de maior representatividade, como ilustrado na Tabela 1. Este exemplo (fator térmico), ainda em desenvolvimento, poderá estar acompanhado de outros dois:

- fator geométrico, que engloba características das placas, tamanhos dos panos e largura das juntas de assentamento;

- fator qualidade, que revela a importância do tipo de controle de execução existente na obra.

Tabela 1 - Exemplo de variáveis de entrada do projeto

\begin{tabular}{l|l|l|l}
\hline \multirow{2}{*}{ Item } & \multicolumn{3}{c}{ Classe de agressividade } \\
\cline { 2 - 4 } & \multicolumn{1}{c|}{ Suave } & \multicolumn{1}{c}{ Médio } & \multicolumn{1}{c}{ Agressivo } \\
\hline $\mathrm{A}=$ Cor da placa & 1. Clara & 2. Média & 3. Escura \\
\hline $\mathrm{C}=$ Flutuação térmica & 1 . até $5{ }^{\circ} \mathrm{C}$ & 2. até $10^{\circ} \mathrm{C}$ & $3 .>10^{\circ} \mathrm{C}$ \\
\hline $\begin{array}{l}\text { Classe de vento pela escala } \\
\text { Beaufort }\end{array}$ & Até 3 & Até 6 & 7 ou superior \\
\hline $\begin{array}{l}\text { Temperatura à época do } \\
\text { assentamento }\end{array}$ & De 10 a $25^{\circ} \mathrm{C}$ & $\begin{array}{l}\text { De } 5 \text { a } 10^{\circ} \mathrm{C}, \\
26 \text { a } 30^{\circ} \mathrm{C}\end{array}$ & $<5{ }^{\circ} \mathrm{C} \mathrm{ou}>30^{\circ} \mathrm{C}$ \\
\hline
\end{tabular}

Fator Térmico $\quad \mathrm{T}=$ ?

Fonte: CE 189:000-03

Uma vez definidos os fatores, individualmente constituídos por ponderações de cada subgrupo de variáveis de entrada, o revestimento poderá ser classificado segundo graus de estabilidade. A tabela, longe de ser conclusiva e/ou exaustiva, tem por objetivo apenas situar o projetista, de forma que fatores importantes não passem despercebidos durante a elaboração do projeto. 


\subsection{Juntas}

Dentre as maiores alterações do texto, o item Juntas mereceu especial atenção. Discussões oriundas de experiências práticas de especialistas no assunto e a compilação de diversas recomendações de normas internacionais deram origem a um novo texto, mais abrangente do que o original. No total, três tipos de juntas serão contempladas, como mostrado na Tabela 2.

Tabela 2 - Configuração típica dos tipos de junta

\begin{tabular}{l|l}
\hline \multicolumn{1}{c|}{ Tipo de junta } & \multicolumn{1}{c}{ Potencial de movimentação } \\
\hline Assentamento (rejunte entre placas) & Muito baixo \\
\hline Movimentação & Baixo a muito alto \\
\hline Estrutural & Alto a muito alto \\
\hline
\end{tabular}

Fonte: CE 189:000-03

\subsubsection{Juntas estruturais}

A junta estrutural é um espaço regular que separa a estrutura em partes independentes, limitando/absorvendo as deformações do edifício como um todo. Normalmente as juntas estruturais são definidas pelo calculista da estrutura de acordo com as movimentações previstas para cada parte da edificação.

Sobre as juntas estruturais, o projeto de revestimento deve contemplar a execução de juntas de movimentação com seccionamento do substrato necessariamente até a base. As características geométricas desta junta precisam ser calculadas levando em consideração as propriedades do selante e as movimentações previstas, lembrando que o uso de selantes pode não ser uma opção viável.

\subsubsection{Juntas de movimentação}

A principal função das juntas de movimentação é subdividir as superfícies revestidas com peças cerâmicas de modo a formar painéis que suportem os efeitos cumulativos das movimentações transmitidas pelo edifício, adequando assim as solicitações impostas à resistência dos materiais empregados. Estas juntas servem também para separar o revestimento cerâmico de outros elementos construtivos da fachada que se movimentam de forma distinta (Medeiros, 1999).

Quando é esperado movimento significativo entre as duas superfícies unidas pela junta, é recomendável que o sulco se aprofunde até atingir a base. Caso isto não ocorra, a movimentação diferencial pode causar a ruptura da camada do revestimento de forma não previsível e comprometer o desempenho do sistema. Assim, além da função geométrica, permitindo a confecção de uma junta de dimensões adequadas, o sulco possui também a função induzir o surgimento das potenciais fissuras de maneira confinada e regular. A Figura 1 apresenta a configuração típica de uma junta de movimentação com corte do substrato até a base.

A Figura 2 ilustra, numa estrutura de concreto armado moldado in loco com vedação em alvenaria, a posição de maior probabilidade do surgimento de fissuras: a interface fundo de viga/fixação da alvenaria. A Figura 3, por sua vez, ilustra a posição da junta em relação ao fundo de viga. 
Figura 1 - Junta de movimentação com corte total do substrato

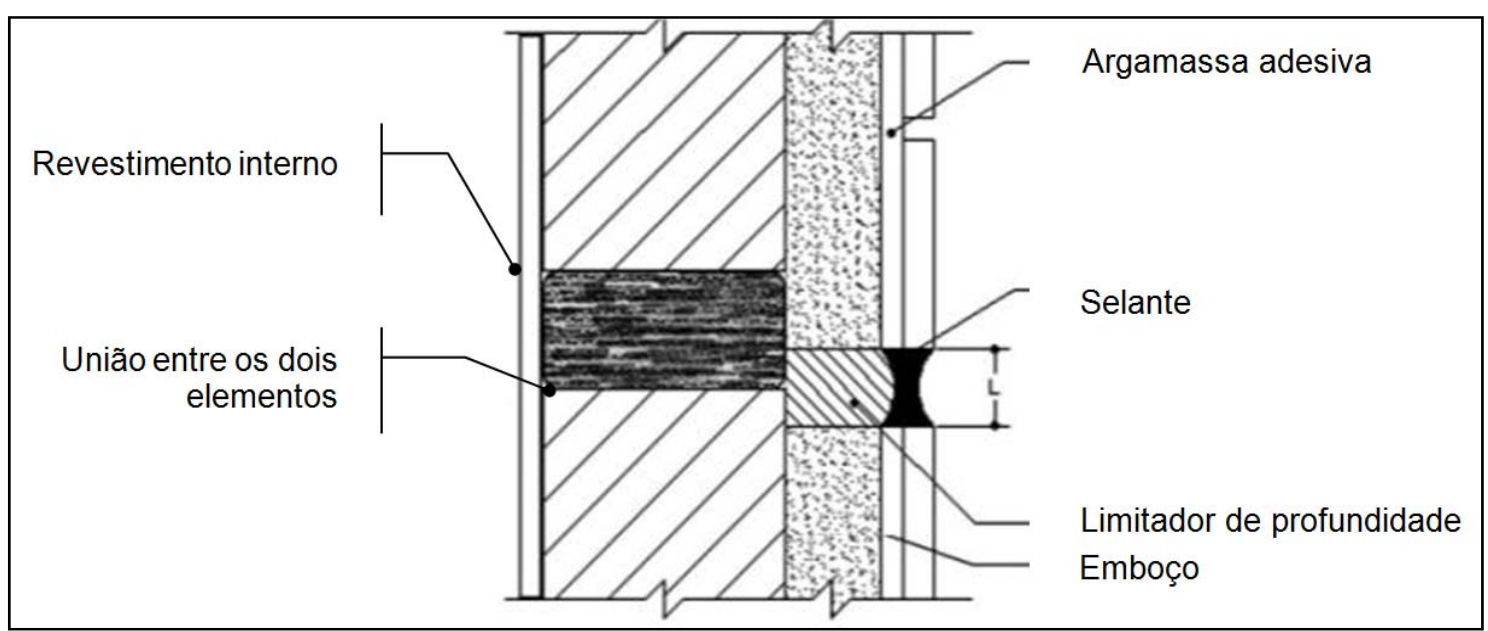

Fonte: NBR 13755 (1996), modificada

Figura 2 - Origem provável da fissura: fundo de viga

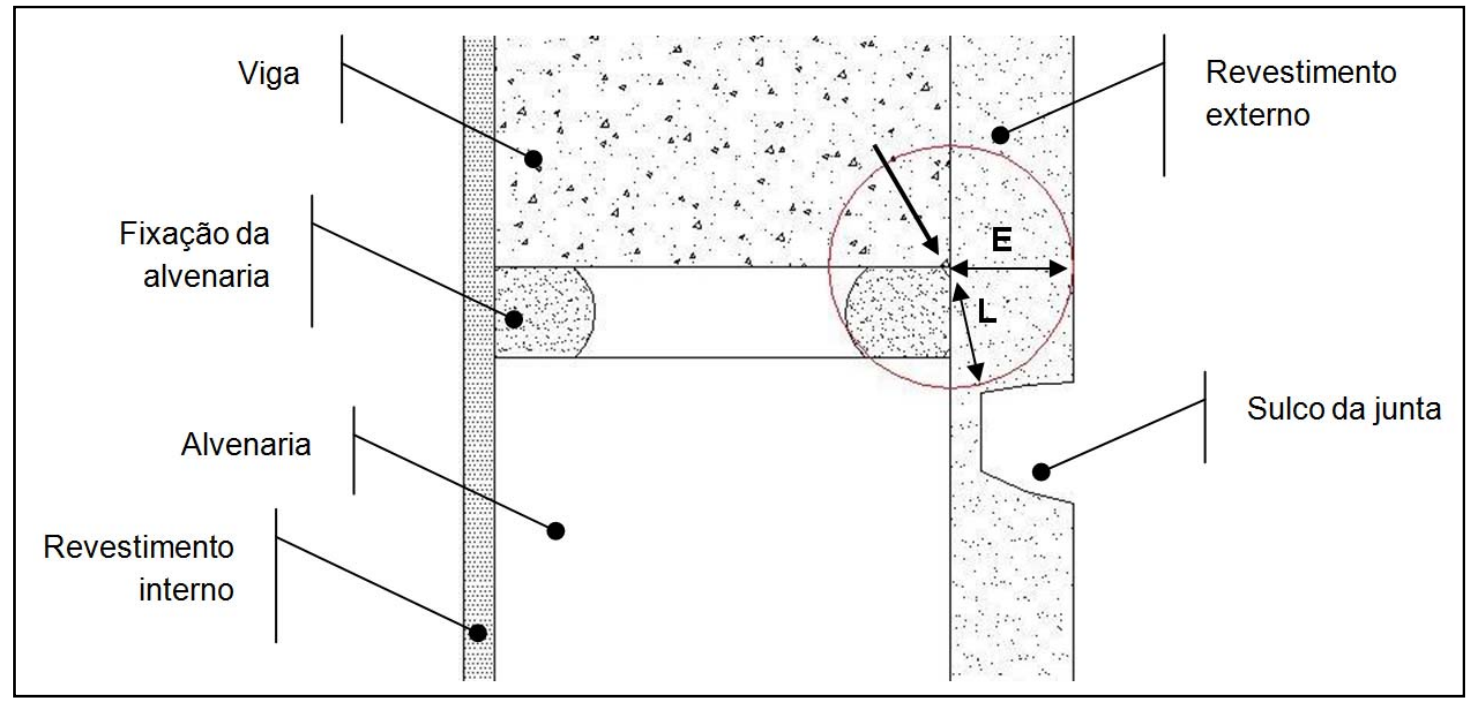

Fonte: autoria própria

Figura 3 - Posição da junta de movimentação em relação ao fundo de viga

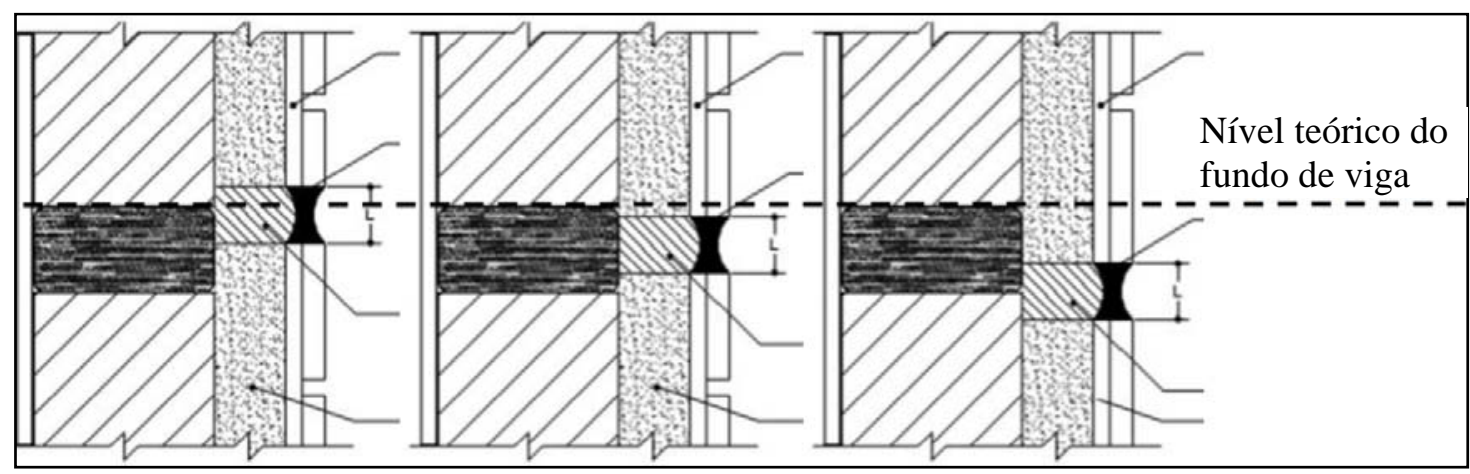

Fonte: NBR 13755 (1996), modificada 
Uma vez que nesta região (fundo de viga/alvenaria) pode haver movimento diferencial e uma fissura tem início, esta fissura tende a percorrer o emboço pelo caminho de menor energia. Assumindo um comportamento homogêneo do emboço nesta região, a fissura aparecerá na região plana da fachada se a distância E (espessura da argamassa) for menor do que a distância que a separa da junta (L). Desta forma, a distância $\mathrm{L}<\mathrm{E}$ é a distância máxima teórica que o sulco deve estar da região mais suscetível à fissuração.

Em outras palavras, o sulco pode estar afastado da região de origem da fissura no máximo de uma distância igual à espessura do emboço para que consiga "atrair" a fissura para seu interior. Este afastamento pode ser dado tanto pelo próprio nível do friso quanto pela profundidade de corte do sulco. Se esta premissa não puder ser atendida devido à posição do friso ou à baixa espessura do substrato, detalhes específicos devem ser previstos em projeto.

Existem, entretanto, casos em que o movimento esperado da junta é pouco significativo, como por exemplo: transição entre elementos distintos do revestimento, entre diferentes tipos de placas, na união das placas com elementos decorativos, nos encontros de revestimentos de piso com paredes, no encontro de placas com pingadeiras e esquadrias etc. Estas juntas, também conhecidas como juntas de transição, são também utilizadas com o objetivo de dividir panos extensos em partes menores.

Embora não contemplada com este nome no novo texto da NBR 13755 (para evitar confusão de nomes com outras bibliografias), estas juntas interrompem apenas as camadas de acabamento (placas) e fixação (argamassa colante) e, portanto, estão sobre um substrato contínuo, sem sulco. Como consequência, para que as duas bordas da junta se movimentem de maneira significativa e solicitem a propriedade elástica do selante, é necessário que haja ruptura do substrato ou destacamento das bordas, o que caracterizaria falha do sistema.

Uma vez que tal fato não ocorre, a movimentação das juntas de transição é muito reduzida e a teoria da adesão do selante em três pontos não se aplica, de forma que a presença de qualquer elemento (fita de fundo de junta, por exemplo) que impeça a adesão do selante ao substrato depende do projetista (Figura 4). As juntas de transição podem ser comparadas a um rejunte de módulo extremamente reduzido e, caso seja considerado prudente pelo projetista, podem ser inseridas entre duas juntas de movimentação, diminuindo o acúmulo de compressão entre as placas cerâmicas de um mesmo pano.

Figura 4 - Exemplo de junta de transição, com e sem fita e fundo

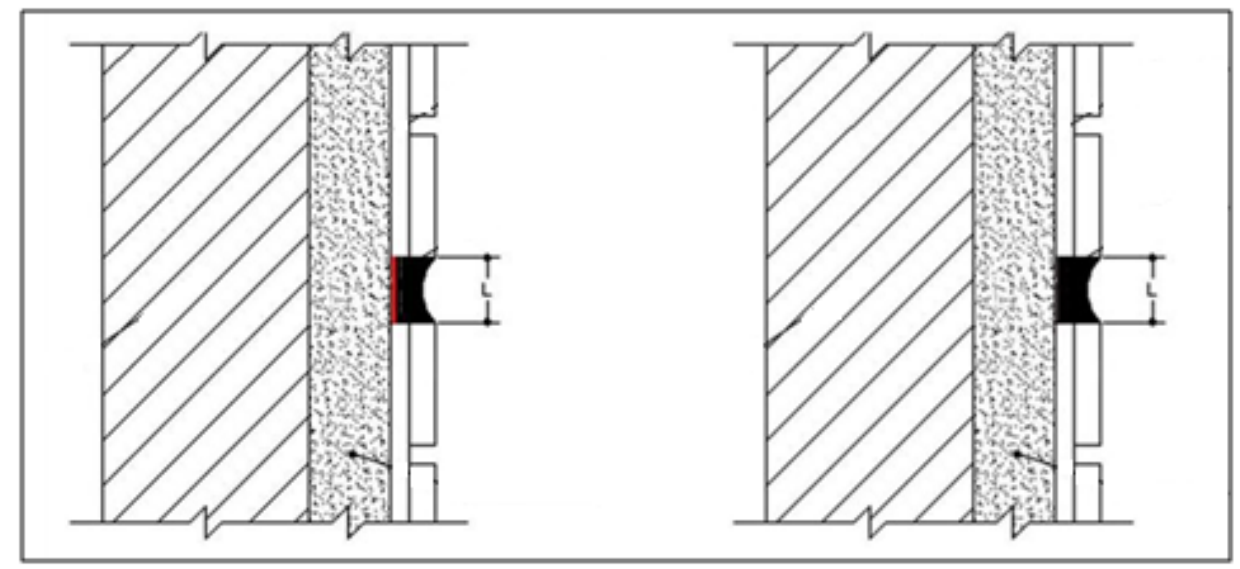

Fonte: NBR 13755 (1996), modificada 


\subsubsection{Posicionamento das juntas}

Tipicamente, juntas horizontais de fachada devem ser posicionadas a cada pé direito do edifício, coincidindo com o fundo de viga, desde que não distanciadas em mais de $3 \mathrm{~m}$. Em caso de pé direito superior a 3m, o posicionamento da junta horizontal, seja ela trabalho ou transição, deve ser especificado pelo projetista do revestimento.

Este tipo de junta, entretanto, pode apresentar movimentação significativa ou não, dependendo do tipo de base, condições de contorno e do próprio revestimento. Assim, nesta posição pode ser especificada uma junta de movimentação com corte total do substrato ou até mesmo uma junta de transição sem corte, onde o sulco se resume ao vão entre duas placas adjacentes aprofundado até a superfície do emboço.

Juntas verticais devem ser posicionadas no máximo a cada $6 \mathrm{~m}$ e sua posição é largamente influenciada por disposições arquitetônicas, como janelas e outros detalhes do revestimento. Como guia orientativo do posicionamento das juntas contempladas na nova NBR 13755, a Tabela 3 expõe algumas situações típicas.

\section{Tabela 3 - Guia típico de uso das juntas de movimentação}

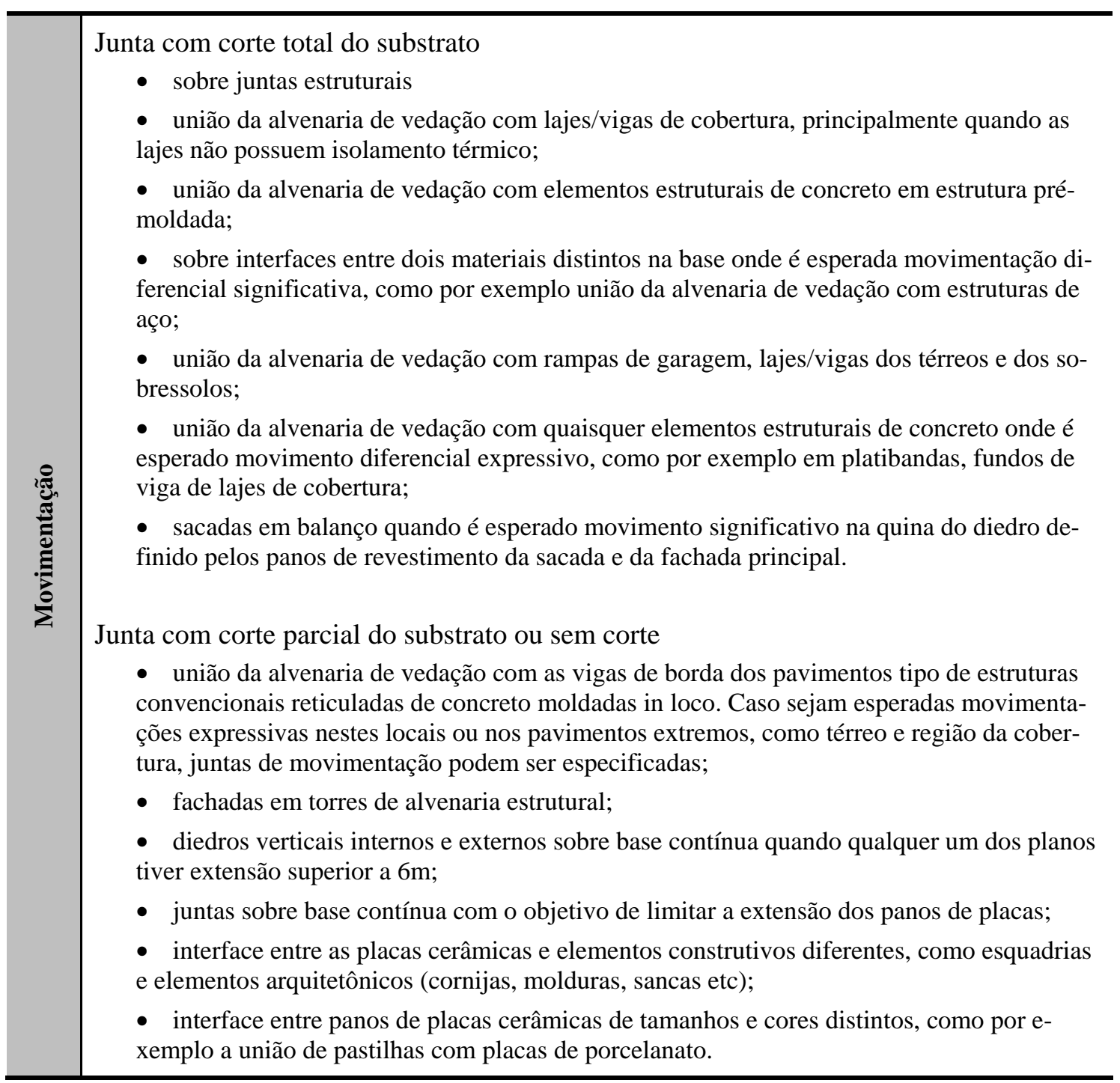

Fonte: CE 189:000-03 


\section{EXECUÇÃO DO REVESTIMENTO}

\subsection{Qualidade do substrato}

Basicamente, o substrato (emboço) para assentamento das placas cerâmicas deve ser preparado de acordo com as normas NBR 7200 (ABNT, 1998) e NBR 13749 (ABNT, 2013). Quando grandes espessuras de argamassa forem necessárias, seja por motivos de regularização da base ou detalhes arquitetônicos, é indicada a aplicação de uma camada de regularização reforçada com tela, preferencialmente metálica. São consideradas grandes espessuras aquelas acima do limite máximo indicado pelo fabricante do produto ou, na ausência deste, $40 \mathrm{~mm}$.

As telas podem ser inseridas por pressão na argamassa fresca ou ser previamente afixadas à base, sendo sua posição final mais comum aquela à meia espessura da camada de regularização, podendo variar de acordo com as especificações técnicas do projeto de revestimento. A posição desejada pode ser garantida por meio do uso de taliscas ou espaçadores pré-ancorados à base. Caso a espessura total do revestimento seja superior a $70 \mathrm{~mm}$, detalhes especiais devem ser obrigatoriamente previstos em projeto, podendo suplantar as especificações contidas no texto da norma.

Por fim, é necessário padronizar o teste de resistência superficial do emboço, que vem sendo executado há vários anos com base no ensaio de aderência hoje existente mas com a alteração de que não existe corte do substrato. Em princípio, serão sugeridos valores de acordo com o tamanho de placa, sendo o mínimo de 0,5MPa.

\subsection{Assentamento das placas}

O assentamento das placas cerâmicas segue o método usualmente empregado com o uso de desempenadeiras denteadas. Serão sugeridos alguns tipos em função do tamanho das placas, como ilustra a Tabela 4.

Tabela 4 - Desempenadeiras denteadas para assentamento

\begin{tabular}{c|c|c|l}
\hline $\begin{array}{c}\text { Placas cerâmicas } \\
\left(\mathrm{cm}^{2}\right)\end{array}$ & Dentes & $\begin{array}{c}\text { Altura mínima } \\
\text { do cordão }\end{array}$ & \multicolumn{1}{|c}{ Aplicação } \\
\hline Pastilhas & $6 \mathrm{~mm}$ & $4 \mathrm{~mm}$ & Seguir recomendação do fabricante \\
\hline até 400 & $8 \mathrm{~mm}$ & $6 \mathrm{~mm}$ & Camada única (substrato apenas) \\
\hline Até 900 & $10 \mathrm{~mm}$ & $8 \mathrm{~mm}$ & Camada única (substrato apenas) \\
\hline Acima de 900 & $10 \mathrm{~mm}$ & $8 \mathrm{~mm}$ & Dupla camada (verso da placa e substrato) \\
\hline
\end{tabular}

Fonte: CE 189:000-03

Entretanto, o número de casos específicos e tamanhos de placas não pode ser abarcado dentro de um único texto, de forma que será inserida uma sugestão de cobrimento do tardoz em função do local de aplicação das placas (Tabela 5), de maneira semelhante ao sugerido pela AS 3958.1 (AS, 2007). O objetivo da desempenadeira denteada se resume em proporcionar uma camada homogênea e de espessura constante de argamassa, mas seu uso não é a única maneira de atingir tal resultado. Desta forma, os dentes das desempenadeiras não estarão restritos ao formato retangular. 
Tabela 5 - Preenchimento mínimo do tardoz das placas

\begin{tabular}{l|c}
\hline \multicolumn{1}{c|}{ Ambiente } & Preenchimento \\
\hline Paredes internas residenciais & $65 \%$ \\
\hline Paredes internas não residenciais & $80 \%$ \\
\hline Áreas úmidas & $90 \%$ \\
\hline Fachadas & $90 \%$ \\
\hline
\end{tabular}

Fonte: AS 3958.1

\section{CONSIDERAÇÕES FINAIS}

O novo texto da NBR 13755 tem a pretensão de tornar-se um guia para a execução de revestimentos cerâmicos. Sabe-se, entretanto, que inúmeras são as variáveis de entrada, variáveis estas que têm maior ou menor importância de acordo com o tipo de edifício e sua localização geográfica no país. Assim, como o texto não pode ser exaustivo, algumas variáveis importantes dentro do contexto do sistema podem ser apontadas, remetendo sua análise integrada ao projetista do revestimento, assim como o fazem o TCNA (2013) e outras normas internacionais.

\section{REFERÊNCIAS}

ASSOCIAÇÃO BRASILEIRA DE NORMAS TÉCNICAS (ABNT). NBR 7200: Execução de revestimento de paredes e tetos de argamassas inorgânicas - Procedimento. Rio de Janeiro, 1998.

. NBR-8214: Assentamento de azulejos. Procedimento. Rio de Janeiro, 1983.

. NBR-9817: Execução de piso com revestimento cerâmico. Rio de Janeiro, 1987.

NBR 13749: Revestimento de paredes e tetos de argamassas inorgânicas - Especificação. Rio de Janeiro, 2013.

NBR-13753: Revestimento de piso interno ou externo com placas cerâmicas e com utilização de argamassa colante - Procedimento. Rio de Janeiro, 1996.

. NBR-13754: Revestimento de paredes internas com placas cerâmicas e com utilização de argamassa colante - Procedimento. Rio de Janeiro, 1996.

. NBR-13755: Revestimento de paredes externas e fachadas com placas cerâmicas e com utilização de argamassa colante - Procedimento. Rio de Janeiro, 1996.

AUSTRALIAN STANDARDS (AS). AS 3958.1: Guide to the installation of ceramic tiles. Australia, 2007. 1992.

AS 3958.2: Ceramic tiles - Guide to the selection of a ceramic tiling system. Australia,

BRITISH STANDARDS INSTITUTE. BS 5385.2: Design and installation of external ceramic and mosaic wall tiling in normal conditions - Code of practice. BSI, 2006.

GOLDBERG, R. P. Direct Adhered Ceramic Tile, Stone, Masonry Veneer, and Thin Brick Facades - Technical Manual. USA, 2011.

MEDEIROS, J.S. Tecnologia e projeto de revestimentos cerâmicos de fachadas de edifícios. 1999. 457f. Tese (Doutorado) - Escola Politécnica da Universidade de São Paulo, São Paulo.

TILE COUNCIL OF NORTH AMERICA (TCNA). TCNA Handbook for ceramic, glass, and stone tile installation. USA, 2013. 